\title{
A escrita de direitos humanos na literatura brasileira contemporânea: o caso das narrativas de vida
}

\author{
Denise Borille de Abreu*
}

Resumo

Este artigo visa estabelecer aproximações entre literatura e direitos humanos, abordando tanto a produção crítica especializada quanto as narrativas literárias no Brasil contemporâneo. Posto que as classes dominantes destituem os sujeitos marginalizados do direito à livre expressão, e partindo da existência de condições desiguais de acesso ao mundo letrado e de representatividade nas configurações sociais do país, desde a época colonial até os dias atuais, buscou-se entender as formas narrativas particulares através das quais os sujeitos excluídos se pronunciam contra os poderes hegemônicos. Nesse aspecto, um enfoque especial é dado às "narrativas de vida" (lifewriting), sobretudo por esse gênero ser alicerçado na subjetividade da experiência do sujeito que narra e aberto a uma linguagem tão inovadora quanto heterogênea, polifônica e inclusiva.

Palavras-chave: Direitos humanos. Narrativas de vida. Lugar de fala. Polifonia. Literatura brasileira.

\section{Human Rights and Life Narratives in Contemporary Brazilian Literature}

\begin{abstract}
This article aims at juxtaposing literature and human rights, addressing both literary narratives and specialized critical production in contemporary Brazil. Since ruling classes dismiss marginalized subjects of their right to free expression, taking into account the existence of unequal conditions of access to the literate world and the lack of representativeness in the arrangement of the country, from the colonial past to the present days, it is the key objective of this article to understand particular narrative forms through which excluded subjects express themselves against hegemonic powers. In this aspect, special focus is given to life-writing forms, mainly because such genre is both based on the subjectivity of the author's experience and open to a language that is just as inventive as heterogeneous, polyphonic, and inclusive.
\end{abstract}

Keywords: Human rights. Life-writing. Place of speech. Poliphony. Brazilian literature.

Recebido: 25/11/2018

Aceito: 12/04/2019

\footnotetext{
* Instituto de Educação Continuada (IEC/PUC Minas). Doutora em Literaturas de Língua Portuguesa (PUC Minas).
} 


\section{Vozes que clamam por direitos essenciais à vida}

Judith Butler conclui sua obra Precarious Life: The Powers of Mourning and Violence (2004) discorrendo sobre a crise contemporânea das Ciências Humanas. Para tanto, a autora propõe um paradigma ético de não-violência, forjado à luz da noção de "face" de Emmanuel Lévinas (1990). O filósofo francês atribuía essa face à alteridade, a um Outro que faz um apelo ético cujo significado consiste em dizer "Não matarás". Esse rosto, entretanto, em sua condição precária, imposta pelos poderes hegemônicos, é desvestido de discurso e descrito de maneira quase fantasmagórica, como uma face que não fala, mas emite vocalizações agonizantes. Um esboço de rosto humano desprovido de fala que, ao sinalizar a intenção de emitir um enunciado, que mais se assemelharia a um murmúrio, implora para que não the retirem a vida.

A noção de "vida precária" de Judith Butler (2004) parece encontrar certa convergência com o conceito de homo sacer, de Giorgio Agamben (2007). O teórico italiano se vale dos estudos de Foucault (2010), sobre a biopolítica, para descrever uma forma de "vida nua", excluída politicamente e suscetível a extermínio pelos poderes soberanos através de várias formas, sendo a linguagem uma delas (AGAMBEN, 2007, p. viii).

A precariedade atribuída à face do outro, conforme formulada por Butler (2004), assim como a vulnerabilidade à morte do homo sacer, proposta por Agamben, nos levam a pensar em como essas vidas ("precárias"; "nuas") são capazes, não obstante as limitações impostas pelos poderes dominantes, de produzir um discurso de sobrevivência e reivindicação de condições dignas de existência. O que compõe, a meu ver, a primeira menção literária de tal intento pode ser encontrado na tragédia grega Antígona, de Sófocles (2014). A protagonista, que reivindica os direitos de enlutar e dar um enterro digno a seu irmão Polinice, dirige uma súplica a Creonte que, entretanto, nega seu pedido em favor das leis vigentes e, em acréscimo, condena-a à morte. O clamor de Antígona constitui uma referência literária, se não inaugural, de grande relevância no que concerne o discurso das vidas excluídas que lutam por direitos humanos. Ao ousar erguer sua voz contra o poder soberano de Creonte, em discordância da lei profundamente desumana que ele impusera, Antígona sinaliza para a importância da formulação de um discurso que se oponha à dominação hegemônica, tanto em TEOR quanto em FORMA, o que lhe fez valer-se do discurso oral em lugar do escrito.

Não parece adequado pensar que a forma como um sujeito excluído se pronuncia contra os poderes hegemônicos replique as formas de expressão dominantes, ao menos não no que diz respeito a alcançar um âmbito mais amplo de autores e leitores. Na crítica literária, tal questão foi abordada, entre outros autores, por Georg Lukács, em A teoria do romance, publicado em 1965. Nessa obra, que é um dos estudos mais conhecidos sobre o romance, Lukács (2000) concebe esse gênero literário como intimamente ligado à ascensão da burguesia, atribuindo-lhe a denominação de "epopeia da era burguesa". Assim sendo, as narrativas produzidas por sujeitos excluídos demandam formas diferentes daquelas que se restringem às elites; tais narrativas urgem um desprendimento das normatividades linguísticas delimitadas às classes brasileiras mais abastadas, cujo acesso à escolaridade sempre esteve assegurado, desde a época colonial até os dias atuais, figurando bem longe de ser um direito pelo qual tiveram que empreender duras lutas. Novas formas narrativas, portanto, fazem-se prementes, sobretudo quando alicerçadas na subjetividade da experiência do sujeito que narra e abertas a um linguagem tão inovadora quanto heterogênea, polifônica e inclusiva. ${ }^{1}$ É nesse espaço de construção de diferença que se inserem as narrativas de vida (minha tradução livre de life-writing), gênero esse

1 De fato, muitas instituições promotoras de direitos humanos vêm fazendo uso de narrativas de vidas para promover contranarrativas que contestem a rasura, o silenciamento e a dominação hegemônicos. É o caso dos trabalhos narrativos conduzidos pela ONU Mulheres; Anistia Internacional (Projeto "Write for Rights"); UNICEF; Change.Org e Médicos sem Fronteiras; entre outras instituições mundialmente conhecidas pela promoção de direitos humanos. 
que abarca produções escritas, como biografias, autobiografias, autoficção, testemunhos, escrita memorialística, escrita de diários e cartas, para citar alguns exemplos, centradas no lugar de fala dos sujeitos que as produzem, aproximando-se, ainda que de maneira encenada, o máximo possível das tramas maleáveis da linguagem oral.

\section{Literatura e direitos humanos no Brasil: perspectivas críticas}

Falar do encontro entre direitos humanos e literatura brasileira contemporânea parece mais válido se levarmos em consideração, primeiramente, algumas das perspectivas críticas apontadas por pesquisadores brasileiros da atualidade. Sendo assim, este artigo busca retratar não apenas exemplos literários que abordem o tema em questão, mas também como o dado assunto tem provocado debates entre teóricos brasileiros da literatura.

Em seu artigo "O direito à literatura", publicado originalmente em 1988, o saudoso crítico Antônio Cândido, professor da Universidade de São Paulo, tem como premissa inicial que a literatura, por si só, constitui um direito humano. Segundo Cândido, isso se dá à medida em que a literatura nos humaniza, sobretudo por ela, entendida enquanto manifestação estética do signo verbal, proporcionar aos seus leitores três prerrogativas fundamentais, a saber: o exercício da reflexão, a aquisição do saber e, por último, o senso da beleza. O autor afirma que:

Acabei de focalizar a relação da literatura com os direitos humanos de dois ângulos diferentes. Primeiro, verifiquei que a literatura corresponde a uma necessidade universal que deve ser satisfeita sob pena de mutilar a personalidade, porque pelo fato de dar forma aos sentimentos e à visão do mundo ela nos organiza, nos liberta do caos e, portanto, nos humaniza. Negar a fruição da literatura é mutilar a nossa humanidade. Em segundo lugar, a literatura pode ser um instrumento consciente de desmascaramento, pelo fato de focalizar as situações de restrição dos direitos, ou de negação deles, como a miséria, a servidão, a mutilação espiritual. Tanto num nível quanto no outro ela tem muito a ver com a luta pelos direitos humanos. (CÂNDIDO, 2011, p. 9).

A inventidade de Cândido, nessa passagem, está em ampliar o campo de percepções da literatura enquanto direito humano, contemplando-a tanto em seu caráter estético ("dar forma aos sentimentos e à visão de mundo") como em seu âmbito social, à medida em que denuncia "situações de restrição dos direitos", como a miséria e a escravidão, sendo que cada um dos domínios não exclui, mas, sim, complementa o outro.

Outra contribuição relevante de Cândido, nesse artigo, foi ter iniciado uma discussão que seria estendida pelos teóricos brasileiros da atualidade por, pelo menos, mais dez anos, a partir da data de publicação do dado texto: a elitização no acesso à erudição, uma questão universal em certa medida, mas certa e infelizmente muito pertinente ao cenário brasileiro desde os tempos coloniais - dos muros silenciosos e perversos existentes entre casa grande e senzala - até os dias ultraconservadores do atual governo, em que esses e vários outros contrastes continuam igualmente ou mais acirrados que no século XVI. Cândido pondera que:

A organização da sociedade pode restringir ou ampliar a fruição deste bem humanizador. $\mathrm{O}$ que há de grave numa sociedade como a brasileira é que ela mantém com a maior dureza a estratificação das possibilidades, tratando como se fossem compressíveis muitos bens materiais e espirituais que são incompressíveis. Em nossa sociedade há fruição segundo as classes na medida em que um homem do povo está praticamente privado da possibilidade de conhecer e aproveitar a leitura de Machado de Assis ou Mário de Andrade. Para ele, ficam a literatura de massa, o folclore, a sabedoria espontânea, a canção popular, o provérbio. Estas modalidades são importantes e nobres, mas é grave considerá-las como suficientes 
para a grande maioria que, devido à pobreza e à ignorância, é impedida de chegar às obras eruditas. (CÂNDIDO, 2011, p. 10).

Em seguida, o crítico advoga pelo igual reconhecimento entre a cultura popular e a erudita, concluindo que a legitimidade desses dois lugares é o que permite o usufruto da literatura como um direito inalienável. Cândido conclui, assim, que:

Portanto, a luta pelos direitos humanos abrange a luta por um estado de coisas em que todos possam ter acesso aos diferentes níveis de cultura. A distinção entre cultura popular e cultura erudita não deve servir para justificar e manter uma separação iníqua, como se do ponto de vista cultural a sociedade fosse dividida em esferas incomunicáveis, dando lugar a dois tipos incomunicáveis de fruidores. Uma sociedade justa pressupõe o respeito dos direitos humanos, e a fruição da arte e da literatura em todas as modalidades e em todos os níveis é um direito inalienável. (CÂNDIDO, 2011, p. 12).

O impacto do artigo de Antônio Cândido foi tal que, após o falecimento do crítico, vários brasileiros renderam-lhe homenagem citando trechos de "O direito à literatura" nas principais redes sociais. Talvez nem tanto pelo seu aspecto inovador, posto que levantou questões já existentes no contexto brasileiro há longa data, mas pela nitidez com que enfocou um tema sobre o qual uma minoria letrada e, portanto, privilegiada, insistia em desviar do olhar.

Alguns anos mais tarde, a crítica literária e professora da Universidade de Brasília, Regina Dalcastagnè, publicou um artigo intitulado "Uma voz ao sol: representação e legitimidade na literatura brasileira contemporânea" (2002). Nele, conforme enunciado pelo próprio título, a autora traz à tona duas indagações de muita valia na produção literária brasileira contemporânea. O primeiro aspecto por ela analisado, o da representatividade, questiona o locus da fala do sujeito marginalizado na ficção: Quem fala? Em nome de quem? Aqui é clara a influência de Gayatri Spivak (2014) na formulação de Dalcastagnè. Igualmente pertinente é a ponderação que ela faz acerca do silêncio dos marginalizados na ficção literária, por sua vez "coberto pelas vozes daqueles que monopolizam o lugar de fala." (DALCASTAGNÈ, 2002, p. 2).

O segundo aspecto levantado pela crítica é o da legitimidade do discurso do sujeito oprimido, posto que não se trata apenas de lhe ser concedida a possibilidade de falar, mas de ter o valor do seu discurso reconhecido (DALCASTAGNÈ, 2002, p. 3). Ela afirma, em seguida, que:

Na narrativa brasileira contemporânea é marcante a ausência quase absoluta de representantes das classes populares. Estou falando aqui de produtores literários, mas a falta se estende também às personagens. De maneira um tanto simplista e cometendo alguma (mas não muita) injustiça, é possível descrever nossa literatura como sendo a classe média olhando para a classe média. O que não significa que não possa haver aí boa literatura, como de fato há - mas com uma notável limitação de perspectiva." (DALCASTAGNÈ, 2002, p. 3).

É digna de admiração a maneira como a autora cutuca essa ferida narcísica da literatura brasileira, por se tratar de uma produção literária feita majoritariamente pela classe média, que a escreve debruçada sobre seu reflexo. Outro acréscimo importante da autora é indagar sobre a ausência de representantes das classes populares nas personagens dessa literatura.

Ao passo que Regina Dalcastagnè estendeu o fio condutor, lançado por Cândido, para uma discussão mais pormenorizada e exemplificada de um assunto pertinente à questão de literatura e direitos humanos no Brasil, o crítico e professor da Universidade de São Paulo Jaime Ginzburg estabeleceu conexões e conclusões bastante contundentes sobre o tema, com o artigo "Literatura e direitos humanos: notas sobre um campo de debates" (2008), que integra sua tese de livre docência.

O texto de Ginzburg inicia-se por um exame das condições de discurso e silenciamento em contextos autoritários. $\mathrm{O}$ crítico refere-se aqui, mais precisamente, às sociedades violentas e repressivas, nas 
quais as vítimas não encontram condições de enunciação de seu sofrimento (GINZBURG, 2008, p.349) para afirmar que:

$\mathrm{Na}$ literatura é constante encontrar personagens que têm necessidades, carências, sofrimentos, e não encontram as palavras adequadas para formular o que precisam. Como se entre pensamento e linguagem ocorressem descontinuidades, abismos. Em pontos tensos podem surgir silêncios, omissões, indeterminações. O sujeito não pode falar tudo, nem ser entendido sempre, no entanto deve achar condições para expressar suas demandas. (GINZBURG, 2008, p. 340).

O entendimento da exclusão social no acesso à erudição, conforme levantado por Cândido (2011) e exemplificado por Dalcastagnè (2002), ganha no artigo de Ginzburg o que penso ser o aspecto pivotal a permear essa problemática: a violência na sociedade brasileira. Outro aporte significativo desse autor é o resgate de perspectivas históricas da nação, ponderando que: "Se a ficção nos leva a pensar que precisamos do letramento para expressar nossos direitos, poderíamos derivar daí a inferência de que fazer parte do mundo letrado facultaria maiores condições de convivência. Isso não é confirmado pelo processo histórico." (GINZBURG, 2008, p. 348).

Ainda de acordo com Ginzburg, "Graciliano Ramos, Clarice Lispector e Sérgio Sant'anna estão entre os autores que despertam desafios interpretativos associados às dificuldades de exercer, no Brasil, a manifestação de direitos humanos." (GINZBURG, 2008, p. 340). Em acréscimo aos autores elencados por Ginzburg - que abordaram as questões dos direitos humanos com teor pungente, porém sob uma forma que exclui aqueles que não tiveram acesso ao mundo letrado - faz-se importante pensar em modelos alternativos às balizas discursivas canônicas, sem os quais alguns ativistas de direitos humanos jamais poderiam se expressar. No que concerne às narrativas de vida, em particular, o conceito derridiano de écriture se aplica à inserção da diferença da história de vida do sujeito que enuncia, seja através da escrita ou da oralidade, (des)construindo e agenciando histórias e subjetividades. Que formas narrativas melhor deram voz à catadora de papel Carolina Maria de Jesus $\left(1960 ; 1961 ; 1963 ; 1986 ; 1996 a ; 1996 b ;\right.$ s/d) ao escravo Mahommah Baquaqua ${ }^{2}$ (LARA, 1988); às detentas que forneceram seus relatos de vida a Nana Queiroz (2015); a Luiz Inácio Lula da Silva (2018) durante seu período no cárcere? Em resposta a esse questionamento, podemos mencionar alguns exemplos de autores de narrativas de vida que merecem figurar em situação de igualdade com os romancistas, conforme citado por Ginzburg, que incluíram o clamor pelos direitos humanos em sua proposta estético-literária.

\section{Conclusão}

Conforme o crítico Jaime Ginzburg salienta, em "Literatura e direitos humanos: notas de um campo de debates" (2008), a ausência de condições de enunciação do sofrimento nas sociedades violentas e repressivas, sobretudo através das formas de linguagem elitizadas, priva as denominadas "vidas precárias" do acesso à produção de uma narrativa considerada aceitável pelo status quo. Ele afirma que "Se a ficção nos leva a pensar que precisamos do letramento para expressar nossos direitos, poderíamos derivar daí a inferência de que fazer parte do mundo letrado facultaria maiores condições de convivência. Isso não é confirmado pelo processo histórico.” (GINZBURG, 2008, p. 348).

Fica claro, conforme as premissas formuladas por Dalcastagnè (2002) e Ginzburg (2008), que a linguagem constitui um componente fundador para ampliar as manifestações literárias acerca da questão de direitos humanos. Portanto, parece válido questionar até que ponto a "malha literária"

2 Refiro-me, aqui, ao relato de Mahommah Baquaqua, escravo africano que descreve sua vida cotidiana no Brasil. Cf. LARA (1988). 
brasileira tem conseguido ser suficientemente flexível para desterritorializar a elitização das narrativas, tornando-as acessíveis às chamadas "vidas precárias" (BUTLER, 2004) ou, ainda, a toda uma legião de homo sacer (AGAMBEN, 2007), posto que são as histórias dessas pessoas, frequentemente destituídas de direitos e negligenciadas pelas autoridades de justiça, que mais carecem de ser ouvidas.

Por mais que as formas eruditas de certas narrativas brasileiras constituam uma manifestação estético-literária de grande impacto - como é o caso da ficção de Clarice Lispector (1998a; 1998b; 1988c; 1964); de Graciliano Ramos, sobretudo em Infância [1945]/(2006); sem falar das representações em versos, a exemplo de Manuel Bandeira, em Belo Belo [1948]/(2014); Carlos Drummond de Andrade, em A rosa do povo [1945]/(2012) ou, mesmo, de Angélica Freitas (2012) em Um útero é do tamanho de um punho - as vozes da grande camada da população brasileira, cujo acesso à erudição é extremamente raro, continuam silenciadas. Como seria possível quebrar esse silêncio do subalterno existente desde os tempos do Brasil-colônia? Talvez seja o caso de se considerar, por exemplo, ampliar a produção de narrativas por meio da oralidade, em que se dá um ato engenhoso e transgressor de (re)criação da linguagem, uma vez que a desinvestem de formalidade e defrontam o modelo canônico-elitista. Nesse aspecto, vale a pena visitar os poemas e os cordéis de Patativa do Assaré (2011; 2008); a escrita memorialística do índio Daniel Munduruku (2016) e da ativista indígena Eliane Potiguara (2018), entre vários outros exemplos de narrativas que rompem com modelos tradicionais para focalizar o local de fala e a subjetividade da história de vida dos sujeitos marginalizados que as narram. ${ }^{3}$

As narrativas de vida (life-writing, em inglês), como biografias, autobiografias, autoficção, testemunhos, escrita memorialística, escrita de diários e cartas, para citar alguns exemplos, conquanto rompem com o aspecto burguês da forma do romance (LUKÁCS, 1965/2000), parecem surgir como formas enunciativas flexíveis que melhor permitem evidenciar, através de um acesso menos elitizado e, portanto, mais democrático ao signo verbal, vidas notáveis, porém precarizadas por fins hegemônicos, como demonstram, na literatura brasileira, as narrativas dos diários da escritora e catadora de papel Carolina Maria de Jesus (1960; 1961; 1963; 1986; 1996a; 1996b; s/d); os relatos biográficos das vítimas da ditadura militar no Brasil, de 1964 a1984 (BRASIL, 2015a; 2015b; 2015c), recolhidos recentemente pela Comissão da Verdade; a autobiografia de Maria da Penha, intitulada Sobrevivi... Posso Contar (2012); o Diário do hospício (1953/2017), de Lima Barreto; a literatura de cordel em Heroínas negras brasileiras em 15 cordéis (2017), de Jarid Arraes; a narrativa autobiográfica de Mahommah Baquaqua (2016), africano trazido para o trabalho escravo em Pernambuco; a escrita memorialística de imigrantes na voz de Zélia Gattai (2009); a escrita biográfica de Daniela Arbex (2014) sobre as histórias de vidas que passaram pelo hospício de Barbacena, somente para citar alguns dos exemplos mais conhecidos. Assim, é possível concluir que, enquanto manifestações literárias, o uso das narrativas de vida parece mais eficaz que a ficção canônica, no que diz respeito a produzir um discurso através do qual o sujeito desprovido de direitos humanos possa expor sua voz, enunciando ele mesmo sua história de vida, numa linguagem que subverta a normatividade.

Em seu artigo intitulado "Oralidade, política e direitos humanos", Anna Christina Bentes (2014) advoga pelo ensino da oralidade da língua portuguesa nas escolas, com o intuito de promover cidadania. A autora afirma que "há inúmeras maneiras de se pensar a oralidade como um locus importante de resistência política, social e cultural e de elaboração de uma gradual consciência dos valores e princípios éticos presentes na Declaração Universal dos Direitos Humanos.” (BENTES, 2014, p. 52). Penso que promover o uso da oralidade enquanto ampliação das possibilidades da linguagem, com o fim de propiciar direitos humanos, poderia abranger outros espaços além da esfera da sala de aula e,

3 Cumpre ressalvar aqui, entretanto, que alguns romances, em caráter mais excepcional, também quebram com a temática canônica burguesa que Lukács (1965/2000) atribui ao gênero. É o caso, dentre outras referências, de Maria Firmina dos Reis (Úrsula, [1859] 2017); Luiz Ruffato (Eles eram muitos cavalos, 2001); Conceição Evaristo (Ponciá Vivêncio, [2003] 2014) e Geovani Martins (O sol na cabeça, 2018). 
sem dúvida, um desses lugares de construção de diferença deveria estar também na produção literária brasileira contemporânea.

Não é objetivo deste trabalho excluir produções ficcionais - tampouco poéticas - brasileiras que contribuem para elucidar a relação entre literatura e direitos humanos, mas, sim, de propor uma ampliação mais significativa do repertório literário nacional já existente sobre o assunto, tomando como premissa a questão pivotal do acesso democrático e universal à linguagem, a fim de que novas formas narrativas, sobretudo as narrativas de vida, iluminem a literatura brasileira como um bem humanizador, ao qual todos os cidadãos brasileiros tenham acesso - e do qual todos possam usufruir.

\section{Referências}

AGAMBEN, Giorgio. Beyond Human Rights. In: VIRNO, P.; HARDT, M. (Eds.). Radical Politics in Italy: A Potential Politics. Minneapolis: University of Minnesota Press, 1996.

AGAMBEN, Giorgio. Homo sacer: o poder soberano e a vida nua. Belo Horizonte: Editora UFMG, 2007.

ANDRADE, Carlos Drummond. A rosa do povo. São Paulo: Companhia das Letras, 2012.

ARBEX, Daniela. Holocausto brasileiro. São Paulo: Geração Editorial, 2014.

ARRAES, Jarid. Heroínas negras brasileiras em 15 cordéis. São Paulo: Pólen, 2017.

ASSARÉ, Patativa. Coleção Melhores Poemas. São Paulo: Global Editora, 2011.

ASSARÉ, Patativa. Cordel. São Paulo: Editora Hedra, 2008.

BANDEIRA, Manuel. Belo belo. São Paulo: Global, 2014.

BARRETO, Lima. Diário do hospício: o cemitério dos vivos. São Paulo: Companhia das Letras, 2017.

BENTES, Anna Christina. Oralidade, política e direitos humanos. In: Ensino de língua portuguesa: oralidade, escrita, leitura. São Paulo: Contexto, 2014. p. 41-53.

BRASIL. Comissão Nacional da Verdade. Relatório final, volume I. Disponível em: <http://www. cnv.gov.br/images/relatorio_final/Relatorio_Final_CNV_Parte_1.pdf $>$. Acesso em: 12 jan. 2015.

BRASIL. Comissão Nacional da Verdade. Relatório final, volume II. Disponível em: <http://www. cnv.gov.br/images/relatorio_final/Relatorio_Final_CNV_Parte_2.pdf $>$. Acesso em: 12 jan. 2015. BRASIL. Comissão Nacional da Verdade. Relatório final, volume III. Disponível em: $<$ http://www. cnv.gov.br/images/relatorio_final/Relatorio_Final_CNV_Parte_3.pdf $>$. Acesso em: 12 jan. 2015.

BUTLER, Judith. Precarious Life: The Powers of Mourning and Violence. London: Verso, 2004.

CANDIDO, Antonio. Vários escritos. Rio de Janeiro: Ouro sobre Azul, 2011.

DALCASTAGNÈ, Regina. Uma voz ao sol: representação e legitimidade na narrativa brasileira contemporânea. In: Estudos de Literatura Brasileira Contemporânea, Brasília, n. 20,: jul.o/ago. p. 33-87. 2002. pp. 33-87.

EVARISTO, Conceição. Ponciá Vivêncio. Rio de Janeiro: Pallas Editora, 2014.

FOUCAULT, Michel. Nascimento da Biopolítica. São Paulo: Edições 70, 2010.

FREITAS, Angélica. Um útero é do tamanho de um punho. São Paulo: Cosac Naify, 2012.

GATTAI, Zélia. Anarquistas graças a Deus. São Paulo: Companhia das Letras, 2009.

GINZBURG, Jaime. Crítica em tempos de violência. São Paulo: EDUSP, 2012.

GINZBURG, Jaime. Literatura e direitos humanos: notas sobre um campo de debates. In: BITTAR,

Eduardo (Org). Educação e Metodologia para os Direitos Humanos. São Paulo: Quartier Latin, 
2008. p. 339-360.

JESUS, Carolina Maria de. Antologia Pessoal. Rio de Janeiro: UFRJ, 1996.

JESUS, Carolina Maria de. Casa de Alvenaria: Diário de uma Ex-favelada. 1a Ed, São Paulo: Francisco Alves, 1961.

JESUS, Carolina Maria de. Diário de Bitita. Rio de Janeiro: Nova Fronteira, 1986. JESUS, Carolina Maria de. Pedaços da fome. São Paulo: Editora Áquila Ltda, 1963. JESUS, Carolina Maria de. Provérbios. São Paulo: s/editora. (s/data). JESUS, Carolina Maria de. Meu estranho diário. São Paulo: Xamã, 1996.

JESUS, Carolina Maria de. Quarto de Despejo: Diário de uma Favelada.São Paulo: Francisco Alves, 1960.

LARA, Sílvia H. (Apresentação). Biografia de Mahommah G. Baquaqua. In: Revista Brasileira de História, São Paulo, v. 8, n. 16, p. 269-283, mar./ago., 1988.

LÉVINAS, Emmanuel. Totalité et infini: essai sur l'extériorité. Paris: Le Livre de Poche, 1990.

LISPECTOR, Clarice. A via crucis do corpo. Rio de Janeiro: Rocco, 1998.

LISPECTOR, Clarice. Felicidade clandestina e outros contos. Rio de Janeiro: Rocco, 1998.

LISPECTOR, Clarice. Laços de família. Rio de Janeiro: Rocco, 1998.

LISPECTOR, Clarice. "Mineirinho”. In: LISPECTOR, Clarice. A legião estrangeira. Rio de Janeiro: Editora do Autor, 1964.

LUKÁCS, Georg. A teoria do romance. São Paulo: Editora 34, 2000.

MARTINS, Geovani. O sol na cabeça. São Paulo: Companhia das Letras, 2018.

MAHOMMAH BAQUAQUA. Revista Brasileira de História. São Paulo. V. 8, n. 16, mar./ago., 1988, p. 269-283.

MUNDURUKU, Daniel. Memórias de um índio: uma quase autobiografia. Porto Alegre: Editora Edelbra, 2016.

PENHA, Maria da. Sobrevivi... Posso contar. São Paulo: Saraiva, 2012.

POTIGUARA, Eliane. Metade cara, metade máscara. Lorena, SP: UKA Editoral, 2018.

QUEIROZ, Nana. Presos que menstruam. Rio de Janeiro: Record, 2015.

RAMOS, Graciliano. Infância. 10. ed. São Paulo: Martin Claret, 2006.

REIS, Maria Firmina. Úrsula: romance. Belo Horizonte: Editora PUC Minas, 2017.

RUFFATO, Luiz. Eles eram muitos cavalos. São Paulo: Companhia das Letras, 2001.

SILVA, Luiz Inácio Lula. A verdade vencerá: o povo sabe por que me condenam. São Paulo: Boitempo Editorial, 2018.

SÓFOCLES. Antígona. São Paulo: Martin Claret, 2014.

SPIVAK, Gayatri. Pode o subalterno falar? Belo Horizonte: Editora da UFMG, 2014. 